\title{
Bullying na Educação Física Escolar. a visão de professores da educação básica
}

\author{
Bullying in school physical education: the view of the elementary \\ school teachers
}

1 Cláudio Severino Delunardo claudiodelunardo@gmail.com

2 Marroni Elen dos Santos

1 Docente do Curso de Educação Física do Centro Universitário de Volta Redonda, UniFOA.

2 Discente do Curso de Educação Física do Centro Universitário de Volta Redonda, UniFOA.

\section{RESUMO}

O presente estudo teve como objetivo compreender a comparência do fenômeno bullying nas aulas de Educação Física Escolar, a partir da visão dos professores que atuam em escolas no município de Volta Redonda, estado do Rio de Janeiro. Para tal, realizou-se uma pesquisa qualitativa, tendo como foco a descrição e interpretação dos significados e experiências dos indivíduos com precisão, por intermédio de entrevista semiestruturada com sete docentes. A partir da exposição feita pelos sujeitos da pesquisa, percebeu-se a eficácia do diálogo com o intuito de prevenir e combater as mais diversas formas de violência, para que o ambiente escolar possa ser um local que possibilite à criança aprender a socializar-se, desenvolver responsabilidades, discutir ideias e, acima de tudo, assumir uma autonomia que permita que o processo de ensino e aprendizagem ocorra de maneira satisfatória para todos.

\section{PALAVRAS-CHAVE}

Bullying; educação física; escola.

\begin{abstract}
This study aims to understand the presence of the bullying phenomenon in physical education classes, from the perspective of teachers who work in schools in the city of Volta Redonda, state of Rio de Janeiro. To this end, a qualitative study was carried out with focus on the accurate description and interpretation of the meanings and experiences of individuals, through semi-structured interviews with seven teachers. From the presentation made by the research subjects, it was noted the effectiveness of dialogue in order to prevent and combat various forms of violence, so that the school environment can be a location that enables the child to learn to socialize, develop responsibilities, discuss ideas and, above all, develop an autonomy that allows the teaching and learning process to take place to the satisfaction of all.
\end{abstract}

\section{KEYWORDS}

Bullying; physical education; school.

\section{Como você deve citar?}

SEVERINO, Cláudio Delunardo; SANTOS, Marroni Elen dos. Bullying na Educação Física Escolar: a visão de professores da educação básica. Cadernos UniFOA, Volta Redonda, n. 29, p. 115-128, dez. 2015. 


\section{INTRODUÇÃO}

A expressão bullying, para Moreira (2010) e Lopes Neto (2011), é empregada com o intuito de detalhar comportamentos agressivos, de ordem física ou psicológica, intencionais e repetidos por um ou mais indivíduos, com a intenção de intimidar outra pessoa, subjugada pela força dos primeiros. A caracterização da intenção por parte dos agressores, além da ausência de justificativas para agressões ou ações desrespeitosas no espaço escolar, também é exposta por Silva (2010), que observa ainda que tais comportamentos podem ocorrer tanto por parte de meninos, quanto por meninas.

Em se tratando da Educação Física em ambiente escolar, Bomfim et al. (2012) mencionam que a correlação entre os discentes é necessária e se faz de maneira singular, visto que as ações ocorridas em aula carecem de capacidade psicomotora e cognitiva por parte dos alunos. Isso acarreta, de acordo com os autores mencionados, uma notoriedade dos alunos com menos habilidade, fato que os tornam acometíveis a tiranias, agressões, exclusão das atividades e comentários perversos.

Levandoski e Cardoso (2010), ao analisarem a forma de administrar situações de conflito por parte dos alunos, questionam até onde se pode diferenciar, no cotidiano das aulas de Educação Física, o jogo da dissimulação ou a brincadeira de um confronto físico, estabelecendo-se uma dúvida quanto ao limite entre o fairplay e a opressão nas relações sociais.

O bullying não deve ser interpretado como uma ação praticada no espaço escolar por uma minoria de indivíduos. Trata-se de um problema social que varia de acordo com o contexto no qual se está inserido (MELO, 2010; LOPES NETO, 2011). Entre as suas consequências, reconhece-se que suas vítimas podem apresentar problemas psicológicos, sociais e de saúde, além da perda de qualidade em seu desenvolvimento, dificuldades de aprendizado, baixa autoestima, quadros esquizofrênicos e tendências suicidas (LEVANDOSKI; CARDOSO, 2010; CARVALHO; SILVA, 2011; BOMFIM et al., 2012)

Como já registrado, o bullying, como uma questão social, necessita de todos os segmentos para combatê-lo, inclusive com a escola se preparando para o enfrentamento do problema (CARVALHO; SILVA, 2011). Segundo Silva (2010), para enfrentar o fenômeno, a escola necessita primeiramente reconhecer a sua existência, bem como as suas consequências. Posteriormente, faz-se necessária, por parte da escola, a capacitação de seus profissionais para identificação, diagnóstico e intervenção das ações ocorridas que se caracterizam como bullying, afırmação corroborada por Bomfım et al. (2012). Finalmente, a escola deve promover uma discussão mais ampla acerca do problema, convidando toda a comunidade escolar a decidir por ações preventivas e imediatas que objetivem o enfrentamento da situação.

A aplicação de treinamentos com o intuito de aprimorar as habilidades sociais dos discentes pode, para Bomfim et al. (2012), representar um mecanismo importante para a diminuição de ações caracterizadas como bullying no espaço escolar. No que tange à Educação Física, sugere-se, como ações pedagógicas, que os conteúdos desenvolvidos não objetivem unicamente a capacidade motora dos discentes, mas que também possam servir de ferramenta para o aprimoramento da capacidade de transformação e interação com o meio (BOMFIM et al., 2012).

O presente estudo pretendeu compreender a comparência do fenômeno bullying nas aulas de Educação Física Escolar, a partir da visão dos professores que atuam em escolas no município de Volta Redonda, estado do Rio de Janeiro. Faz-se necessário salientar que, por se tratar de uma pesquisa qualitativa, objetiva-se aqui a compreensão da realidade e ser investigada, bem como a sua interpretação (SILVA; DAGOSTIN; NUNEZ, 2009). 0 estudo justifica-se pela sua relevância como produção de conhecimentos voltados para a área da Educação Física Escolar, além da sua contribuição, quanto ao diagnóstico do fenômeno bullying nas aulas da referida disciplina. 


\section{METODOLOGIA}

Para a obtenção dos dados, fez-se uso de uma entrevista semiestruturada como instrumento. As entrevistas foram realizadas de acordo com as necessidades e possibilidades dos docentes envolvidos na pesquisa, a considerar, principalmente, a disponibilidade de tempo dos sujeitos. A construção do instrumento de coleta de dados baseou-se nas categorias empíricas construídas a partir de um conjunto de pressupostos ligados ao estudo bibliográfico (AGEE, 2009; SOUZA JUNIOR et al., 2010).

Por se tratar de uma pesquisa qualitativa, Borreani et al. (2004) observam que o seu objetivo é referente ao aprofundamento acerca da compreensão da complexidade das realidades humanas. Para o desenvolvimento da presente pesquisa, foram utilizados critérios, categorias e parâmetros para se verificar como uma opinião ou comportamento se manifesta.

Ainda sobre a pesquisa qualitativa, Agee (2009) menciona que nesse tipo de investigação há o envolvimento de questões que contemplam o porquê e o como das interações humanas. Para isso, buscam-se as opiniões dos sujeitos no sentido da compreensão das perspectivas deles em relação às mudanças sociais.

\subsection{Participantes}

Os sujeitos da pesquisa consistiram em professores graduados em Licenciatura em Educação Física que lecionam na Educação Básica, ou seja, Educação Infantil, Ensino Fundamental e Ensino Médio. 0 número de docentes entrevistados foi sete $(n=7)$ e o critério de inclusão foi ser efetivo do quadro de docentes de escolas localizadas no município de Volta Redonda. Ressalta-se que, no decorrer da coleta de dados, um professor se recusou, por razões pessoais, a fazer parte da pesquisa.

Nota-se que somente participaram da pesquisa os professores que cumpriram com toda a documentação necessária, de acordo com o Comitê de Pesquisas em Seres Humanos do Centro Universitário de Volta Redonda - UniFOA, submetido e aprovado sob o Certificado de Apresentação para Apreciação Ética $n^{\circ}$. 37605214.5.0000.5237.

\subsection{Métodos de coleta de dados}

As entrevistas foram realizadas com os docentes com o intuito de compreender a comparência do fenômeno bullying nas aulas de Educação Física Escolar. Na entrevista foram aplicadas 3 (três) questões associadas ao tema central da pesquisa, sendo elas: A) Caso haja ocorrências de situações de bullying em suas aulas, a que você atribui a incidência do fenômeno durante as mesmas? B) Você julga que discentes vítimas de bullying podem ter sequelas e prejuízos futuros? Pode citar exemplos? C) Quais devem ser as ações do profissional de Educação Física quanto ao combate ao bullying no espaço escolar?

A construção dos instrumentos de coleta de dados baseou-se nas categorias construídas a partir do referencial teórico relacionado aos processos metodológicos de avaliação. A partir da designação de algumas questões prioritárias que passaram por um processo de análise e seleção, no qual algumas foram refeitas ou excluídas, as categorias empíricas organizadas foram: o bullying nas aulas de Educação Física, as possíveis consequências da prática do bullying nas aulas de Educação Física e ações pedagógicas em relação ao bullying nas aulas de Educação Física.

Com o intuito de construir o instrumento de avaliação que foi utilizado para a coleta de dados, foram seguidos os seguintes procedimentos: planejamento do roteiro da entrevista; validação do ins- 
trumento; seleção dos entrevistados; agendamento das entrevistas; cronograma de execução; registro das respostas por meio de gravações; apuração dos dados obtidos.

A coleta de dados foi realizada por meio de entrevista registrada em áudio. Após esse procedimento, os dados obtidos foram criticados à procura de falhas sistemáticas no planejamento, aquisição e armazenamento. Para a coleta foi necessário: preenchimento do termo livre esclarecido de concessão de direitos; assinatura da carta de anuência; concessão da entrevista.

Foram registradas entrevistas audiogravadas com quatro professores do sexo masculino e três do sexo feminino, sendo que a duração média das entrevistas foi de seis minutos. Após a realização das entrevistas, os dados coletados foram transcritos por meio de digitação para posterior análise. É necessário considerar que o gravador oportuniza a coleta das respostas dadas pelos participantes sem que se perca qualquer dado para a realização das entrevistas. 0 equipamento utilizado foi um aparelho digital Sony ICD-PX312F 2GB.

\subsection{Validação do instrumento}

Para a validação do instrumento de coleta de dados, foi ratificado qualitativamente por dois professores com notório conhecimento sobre a área de estudo, que sugeriram e orientaram modificações, no sentido de tornar o guia de entrevista mais objetivo e coerente com o objetivo do estudo.

\subsection{Métodos de tratamento de dados}

Após o procedimento de coleta de dados, fez-se necessário a soma e processamento das informações obtidas. Esse processo iniciou-se a partir de uma análise crítica dos dados, o estabelecimento de critérios de classificação e o tratamento estatístico que possibilitou uma observação detalhada das hipóteses elencadas.

Os dados colhidos nas entrevistas foram submetidos a uma análise de conteúdo pelo programa NVIVO 10, software especificamente projetado para analisar os dados qualitativamente (BOYLE et al., 2008).

\subsection{Análise dos dados}

Após a organização das entrevistas devidamente transcritas, realizou-se a etapa que consistiu na criação de categorias (códigos) e a análise das transcrições com os recortes devidamente inseridos nas categorias criadas. A concepção de categorias, de acordo com Bardin (2011), oportuniza a compreensão dos significados das informações obtidas, colocando-as adequadamente em seus respectivos contextos.

Baseado no referencial teórico, o presente estudo, conforme mencionado anteriormente, baseouse em três categorias, sendo elas: o bullying nas aulas de Educação Física; possíveis consequências da prática do bullying nas aulas de Educação Física; ações pedagógicas em relação ao bullying nas aulas de Educação Física.

De acordo com Minayo (2010) e Thomas, Nelson e Silverman(2012), as categorias foram escolhidas a partir de sua finalidade operacional, partindo da premissa de que elas possuíam características que as possibilitavam emergir de e no processo de análise. Diante disso, relevou-se a possibilidade de, após o diálogo entre o referencial teórico e os dados obtidos, estabelecer-se a compreensão acerca do tema a ser investigado (Figura 1). 
Figura 1 - Modelo de identificação das categorias analíticas para conhecimento do objeto de estudo.

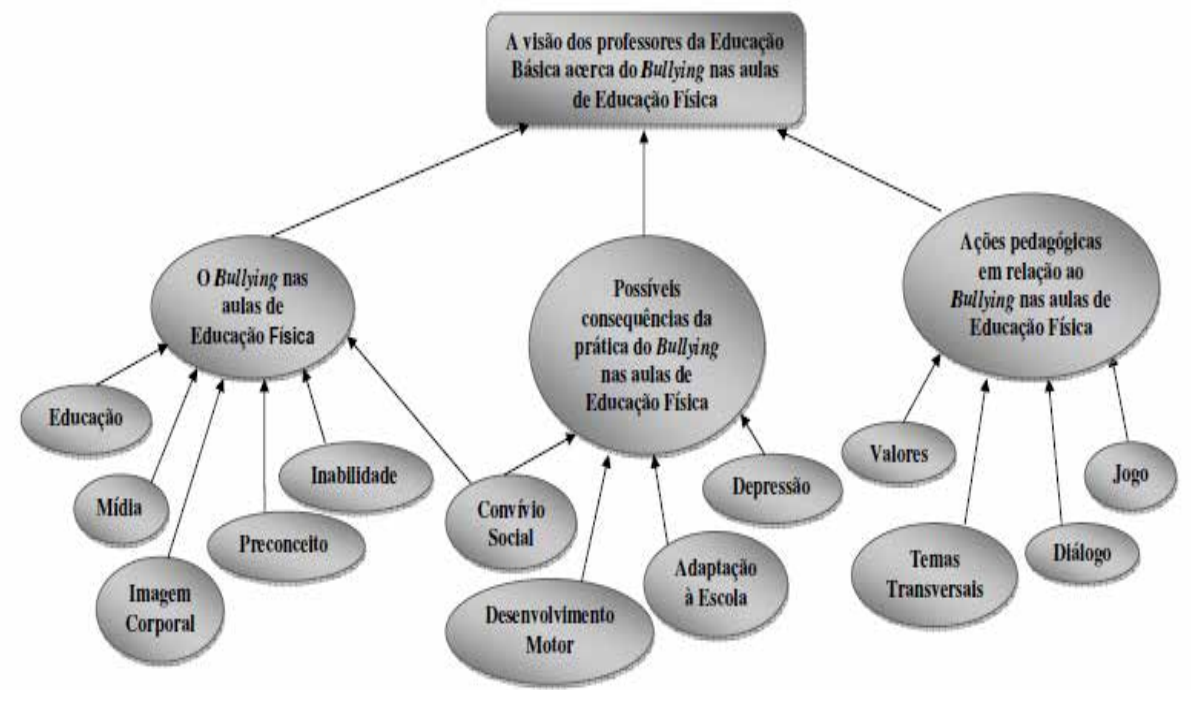

Fonte: dos autores.

\section{RESULTADOS E DISCUSSÃO}

Sobre a caracterização da amostra, dos docentes entrevistados, 3 ministram aulas na rede municipal de ensino; 2 , na rede estadual e; 1 , em ambas as redes públicas, sendo que todos são professores de instituições particulares. Dos sujeitos participantes da pesquisa, apenas 1 leciona unicamente em escolas privadas.

No que tange à qualificação dos docentes participantes da pesquisa, observou-se uma incidência de especialistas (lato sensu) em comparação a graduados e mestres (stricto sensu). Dos professores entrevistados, 5 são especialistas, 1 é graduado e 1 é mestre.

Após a caracterização da amostra, realizou-se a análise das três categorias vinculadas ao propósito da presente pesquisa. 0 quadro 1 apresenta a incidência das respostas associadas a cada categoria.

Tabela 1 - Incidências das respostas apresentadas.

\begin{tabular}{|c|c|}
\hline \multicolumn{2}{|c|}{ O bullying nas aulas de Educação Física } \\
\hline Educação (3) & Preconceito (2) \\
\hline Mídia (3) & Inabilidade (3) \\
\hline Imagem corporal (3) & Convívio social (4) \\
\hline \multicolumn{2}{|c|}{$\begin{array}{c}\text { Possíveis consequências da prática do bullying } \\
\text { nas aulas de Educação Física }\end{array}$} \\
\hline Convívio social (5) & Adaptação à escola (2) \\
\hline Desenvolvimento motor (2) & Depressão (1) \\
\hline \multicolumn{2}{|c|}{$\begin{array}{l}\text { Ações pedagógicas em relação ao bullying nas aulas de } \\
\text { Educação Física }\end{array}$} \\
\hline Valores (3) & Jogo (2) \\
\hline Temas transversais (3) & Diálogo (5) \\
\hline
\end{tabular}

Fonte: dos autores. 


\subsection{O bullying nas aulas de Educação Física}

Sobre a presença do bullying na aulas de Educação Física, não foi observada uma relevante predominância de uma determinada razão que justifique a presença do referido fenômeno. Dos docentes entrevistados, 4 apontaram as relações entre os indivíduos como um fator determinante para a prática do bullying, enquanto a educação, a influência da mídia, a imagem corporal do aluno e a falta de habilidade motora foram mencionadas em 3 depoimentos. 0 preconceito também foi citado como uma das possíveis causas da manifestação do bullying, com 2 incidências.

Os resultados provaram que, em diversas ocasiões, a agressão social se faz presente no ambiente escolar, talvez, segundo Leite (2011), devido ao fato de que ela ocorre no cotidiano dos indivíduos, ocasionando a apropriação de gestos nem sempre recomendáveis por parte dos discentes, justificados por uma suposta normalidade. 0 mesmo autor aponta que esse procedimento ocasiona a transformação do não social em um procedimento aceitável e até recomendado. Da mesma opinião compactua Silva (2010), que afirma ainda que o referido cenário é resultado das mudanças sociais, culturais, econômicas e política que criaram novos valores e referências, lembrando que a escola apresenta a tendência em reproduzir aspectos da sociedade como um todo.

De acordo com as opiniões proferidas pelos participantes da pesquisa, tal realidade ocorre, até certo ponto, em função da mídia, que cria parâmetros determinantes para o comportamento transgressor por parte da população infanto-juvenil:

\footnotetext{
Acredito que seja em função da mídia, porque hoje em dia nós temos estereótipos de corpo, padrões e normas seguidas que são consideradas corretas. Então acho que crianças que não seguem esse padrão, não porque querem, mas enfim, por alguma razão, que não é referente à nossa alçada. Eu acho que elas sofrem por causa disso (P. 4).
}

Leite (2011) cita, sobre a mídia, que constantemente são apresentados vídeos contendo cenas agressivas com contextos antissociais, sempre com o intuito de garantir que tal vilania seja repetida quantas vezes foram acessadas a mídia.

A imagem corporal foi mencionada por 3 entrevistados, como um agente causador da presença do fenômeno bullying nas aulas de Educação Física. Todos mencionaram o suposto excesso de peso dos alunos como uma razão para o comportamento depreciativo dos alunos agressores em relação às suas vítimas:

O bullying pode ocorrer em relação ao sobrepeso. A gente tenta argumentar e dizer sobre qualidade de vida e o respeito ao corpo, as individualidades (P. 3).

A Educação Física no ambiente escolar deve não somente desenvolver a capacidade motora dos discentes, mas também ser responsável pela transformação social dos mesmos (BOMFIM et al., 2012; COSTA et al., 2012). Levantar questões voltadas para entendimento de que alterações fisiológicas podem ocasionar ganho de peso deve fazer parte do conjunto de atribuições do professor, discutindo com os alunos que a formação da autoimagem corporal está diretamente ligada à maneira como a sociedade estipula como um corpo esteticamente aceitável. Em muitas ocasiões, apelidos depreciativos devido ao excesso de peso dos alunos podem acarretar transtornos alimentares, como a anorexia e a bulimia, motivadas pelo desespero que o indivíduo tem de engordar (SILVA, 2010).

Ainda a respeito de manifestações de bullying ocorridas nas aulas de Educação Física, 3 participantes observaram que elas acontecem em função da dificuldade apresentada por alguns alunos em atividades, nas quais a falta de habilidade é colocada em evidência: 
Na educação física, por tratar com demonstrações, de uma certa preponderância em habilidades, acontece esse tipo de situação de algum aluno, verificando que um amigo não realizou a tarefa de uma forma como ele achava que devia ser realizada para a equipe que ele participa, ou o grupo onde que ele está, possa ter um resultado melhor, às vezes a criança verbaliza (P. 2).

Nas atividades realizadas durante as aulas de Educação Física, os discentes são exigidos quanto à sua capacidade psicomotora para o cumprimento dos objetivos propostos. Por isso, os alunos menos habilidosos acabam sendo vítimas de agressões, intimidações e, até mesmo, exclusão das atividades (BOMFIM et al., 2012).

Nota-se que, a partir do momento em que, na perspectiva de Oliveira e Daólio (2010), ocorre a padronização de movimentos que exigem certa habilidade, acaba-se desvalorizando determinados repertórios corporais. Nesse caso, de acordo com a realidade observada, há a presença de manifestações de bullying. Nesse contexto, Bomfim et al. (2012) e Moura (2011) observam que, no cotidiano da Educação Física, condutas agressivas contra alunos que apresentam, no entendimento de seus pares, desempenho ineficaz, são motivadas pelo incentivo à competição. Percebe-se, novamente, a relevância do papel do professor na condição de mediador de possíveis conflitos ocorridos no decorrer das aulas.

O convívio social também foi mencionado por 4 participantes, como possível causa para manifestações de bullying: "A gente atribui a incidência desse fenômeno pelas relações naturais entre as pessoas" (p. 2).

Para Moura (2011), a identidade do indivíduo é caracterizada pelo seu vínculo a um determinado grupo social. No instante em que esse vínculo acarreta em manifestações de preconceito, isso afeta a construção da identidade da vítima, prejudicando as suas relações sociais. 0 mesmo autor observa ainda que, em grupo social, o respeito entre seus integrantes nem sempre alcança um real valor, pois, para tal, há a necessidade de que ele seja vivenciado, de forma que se torne significativo para os alunos. Em relação ao ambiente escolar, aqui em particular as aulas de Educação Física, Lopes Neto (2011) salienta a relevância da convivência na organização das relações interpessoais. Segundo o autor, as boas condições para a concretização de relações positivas entre os alunos são reforçadas pela convivência frequente e contínua.

Sobre o preconceito, mencionado em 2 ocasiões pelos entrevistados, observou-se a sua relação com questões raciais e religiosas: "E por incrível que pareça, até nessas situações de cor, de raça, credo, até religião" (p. 1).

Essa questão motiva a discussão quanto ao fato de que o comportamento discriminatório mencionado talvez não deva ser compreendido como a causa de um problema, mas a consequência da inexistência, nas aulas de Educação Física, de discussões sobre condutas vinculadas a estereótipos sociais.

Sobre aspectos associados à religião, percebe-se que a presença de grupos religiosos minoritários e a laicização são temas de debates frequentes no âmbito escolar, sendo a Educação Física um amplo cenário para eles, em função da associação entre corpo e religião (SILVA; SILVA, 2009). Os referidos autores indicam ainda que a reflexão acerca da relação entre religião, Educação Física e, também, o folclore, permite o diálogo e, principalmente, o respeito à diversidade. Nesse caso, os conteúdos trabalhados no decorrer das aulas deveriam não somente privilegiar a capacidade motora dos discentes, mas também o desenvolvimento do pensamento crítico e a capacidade de transformação social (BOMFIM et al., 2012; BOZI et al., 2008).

Em relação ao racismo, Boziet et al. (2008) afirmam que uma pessoa negra encontra dificuldades em entrar na mesma escola que um indivíduo branco. Quando isso ocorre, as críticas ocorrem para humi- 
Ihar e excluir aqueles que não se adequam aos padrões impostos. Na Educação Física, observa-se esse quadro com frequência, tendo em vista que as atividades que exigem contato físico e possibilitam a visão do corpo de forma mais espontânea estimulam comportamentos incomuns no interior das salas de aula.

\subsection{Possíveis consequências da prática do bullying nas aulas de Educação Física}

Em relação às possíveis consequências da prática do bullying nas aulas de Educação Física, observouse, entre os docentes entrevistados, que o convívio social tem o maior índice de sequelas, prejudicando assim o estabelecimento de novas amizades e fazendo com que a criança se sinta excluída, tornando-se, assim, adultos com grandes dificuldades sociais. Desenvolvimento motor e adaptação à escola foram citados em 2 depoimentos. A depressão também foi tida como consequência, apontada por 1 docente entrevistado.

Nesse contexto, Teixeira $(2011$, p.55) afirma que as consequências para os alunos vítimas de bullying,são devastadoras. "Esses estudantes experimentam um grande sofrimento psíquico que pode interferir intensamente no desenvolvimento social, emocional e em seu desempenho escolar".

Mencionado por 5 entrevistados, o convívio social prejudicado torna os indivíduos com mais dificuldades de interação, tornando-os introspectivos: "A questão do social está muito impregnada. Então esse tipo de aluno que sofre algum tipo de bullying acaba se afastando do social, acaba se afastando dos colegas" (p.1).

Citado por 2 dos entrevistados, o desenvolvimento motor, como um importante comportamento de habilidades e capacidades físicas, fica prejudicado pelas ações do bullying.

Ele acaba prejudicando também no motor, no procedimental, porque se a criança não consegue se relacionar com o outro dentro das aulas ou ela começa a se afastar do outro por essas questões do bullying, ela também, pela característica das nossas aulas, pela característica da nossa área, ela se afasta também do fazer. (p. 1).

É no contexto escolar que existe maior incidência de bullying, sendo ela na prática de algum tipo de atividade física, no recreio e/ou durante as aulas de Educação Física, onde ocorre uma intensa interação social na realização das atividades, o que pode se tornar um momento problemático, quando se diz respeito ao bullying, geralmente com os alunos menos habilidosos, com um desenvolvimento motor de nível mais fraco, tornando o aluno mais vulnerável a agressões, intimidações, comentários maldosos, exclusão das atividades, devido a sua coordenação motora. Para Medeiros et al. (2014), as crianças vítimas de bullying, com frequência, são mais propensas a não praticarem atividade física e a frequentarem menos as aulas de Educação Física, o que acaba acarretando consequências negativas para o desenvolvimento motor e para a saúde desses indivíduos.

Entre as várias consequências, Fante (2005) deixa claro que, para as vítimas de bullying, as consequências são inúmeras, dependendo de como recebem as agressões e de como reagem em relação a seus agressores. A autora afirma que as consequências para as vítimas são graves e abrangentes, podendo ocasionar desinteresse pela escola, déficit de concentração e aprendizagem, queda do rendimento escolar, absentismo e evasão escolar. 0 abandono da escola, o desdém pelo estudo torna pessoas ignorantes, levando a vítima a pensar que, longe da escola, ela estará imune ao problema.

De acordo com 2 participantes entrevistados, o fenômeno bullying pode causar diversos fatores negativos, entre eles, a não adaptação da vítima à escola, causando a desistência.

Toda forma de agressão intencional e repetida pelos alunos causa angústia e humilhação ao outro, fazendo com que essa vitima venha a ficar intimidada, isolada, discriminada com dificuldade de novas amizades, vindo até a abandonar a escola, talvez até os estudos (P.6). 
Tal fenômeno acarreta manifestações, como a depressão, consideradas de muito risco, pois podem causar traumas permanentes: " $E$ em casos mais graves pode acabar até desenvolvendo uma série, uma séria depressão" (p. 6).

Lopes Neto (2011) observa que algumas situações mais extremas são passíveis de ocorrer, como a fobia escolar, em que o medo, a ansiedade e as manifestações depressivas incapacitem crianças e adolescentes a frequentar a escola. Para Teixeira (2011), quando há um quadro grave depressivo instalado e quando os níveis de estresse são muito elevados, a prevalência de índices de pensamento de suicídio é maior.

\subsection{Ações pedagógicas em relação ao bullying nas aulas de Educação Física}

No que diz respeito às ações pedagógicas em relação ao fenômeno bullying presente nas aulas de Educação Física, o diálogo, de acordo com 5 docentes participantes, foi destacado como primeira atitude a ser tomada.

O ideal é conversa, muita conversa, muito diálogo, explicações e mostrar para os alunos o que isso pode acarretar futuramente, porque eles ainda não têm essa noção e fazê-los entender que é sofrimento pra quem é vítima de bullying e que eles também podem sofrer a qualquer momento e em qualquer idade (P.4).

O diálogo é uma das formas mais eficazes de se combater e prevenir os casos de bullying. (SILVA, 2010; LOPES NETO, TEIXEIRA, 2011). Para Silva (2010), o diálogo deve começar pela vítima, demonstrando total compreensão e disponibilidade para ajudá-la, de forma que ela se sinta segura para falar sobre seus sentimentos frente aos ataques que sofre. Segundo a autora, é preciso criar um clima de compreensão para que eles possam revelar seus pensamentos, suas motivações e a avaliação que fazem de suas atitudes. É importante que o entrevistador seja firme para expor aos agressores todas as consequências que podem advir de seu comportamento inadequado. Em situações mais graves, quando a postura do agressor é mais resistente, é necessário ir além do diálogo no espaço escolar, e buscar auxilio de outros profissionais, instituições comprometidas com a proteção da criança e do adolescente ou até mesmo recorrer ao Conselho Tutelar.

Também destacado durante a presente pesquisa, valores e temas transversais foram citados por 3 professores participantes, além da aplicação de jogos, mencionados por 2 docentes, como práticas eficientes na redução de atitudes preconceituosas.

Como importante forma de ação pedagógica no combate ao fenômeno bullying, os valores, de acordo com os docentes entrevistados, é visto como essencial para compreensão dos limites, próprios e alheios, durante as aulas de Educação Física:

A gente vê hoje, infelizmente, uma sociedade muito pouco preocupada em trabalhar os valores, que são essenciais para compreensão da gente mesmo e do outro com os seus limites, deficiências, isso a gente não percebe mais. A gente percebe os setores da sociedade desconectados aos trabalhos relacionados às virtudes. Com isso se percebe uma intolerância maior da criança (p.2).

Em entrevista concedida à Revista EF, a professora Tânia Netto apontou que a Educação Física não pode se eximir da responsabilidade de colaborar com os valores na formação dos alunos e, por suas características e ações curriculares, essa condição é considerada de grande relevância na construção do processo de educação de crianças, jovens e adultos. Acredita-se que o diálogo ainda seja a melhor opção para a solução de conflitos, que são facilmente identificados nas aulas de Educação Física e, também, a superação da discriminação deve ser trabalhada em atividades coletivas e de aproximação entre agressor e vítima. 
A escola não pode ser um espaço de homogeneização, mas sim de resgate e respeito aos valores $\mathrm{e}$ às diferenças. As pessoas precisam aprender a reconhecer, assumir e aceitar a sua diferença, mas também necessitam aprender na escola a reconhecer como normal e natural a diferença de seus pares para poder respeitá-la (MASCARENHAS, 2006). Dessa forma, os discentes têm direito a um ambiente escolar com a devida solenidade, seguro, que lhes favoreça uma convivência interpessoal de respeito à dignidade humana e à cidadania, caracterizada pela aceitação e o acolhimento das diferenças individuais, variáveis essenciais para a saúde emocional e o bem-estar psicossocial durante a realização das atividades.

Sobre os temas transversais, 3 docentes participantes concordam que durante as aulas de Educação Física é importante que as atividades sejam focadas nos conceitos e valores básicos à democracia e à cidadania da sociedade contemporânea.

\footnotetext{
Eu vejo até como uma obrigação também, porque temos os temas transversais, que devemos dar conta também. Então, quando você fala de temas transversais deve-se discutir a questão da pluralidade cultural. Entra nesse item, a questão de ética e cidadania, quer dizer, nesse problema, a gente acaba tendo, podendo e devendo discutir isso dentro das nossas aulas dessa maneira (P.1).
}

Durante as aulas de Educação Física, o tratamento do bullying como um tema transversal leva em conta a necessidade de apresentar e explicitar os valores fundamentais como o respeito mútuo, a solidariedade, cooperação, a justiça e o diálogo, uma vez que a moral está presente em todas as experiências humanas e precisa estar enfocada durante todo o convívio escolar (MASCARENHAS, 2006). Porém, para Fante (2005), muitos professores enfrentam problemas em utilizar no cotidiano de suas aulas os temas transversais, como meio de compreensão de outras áreas, como educar em valores, por não saberem como abordá-los, o que resulta na deficiência de tornar capaz outros modelos educativos que sensibilizam, estimulam e orientam as atitudes individuais ou coletivas dos alunos.

Sendo uma área que possui um enorme campo de ensino e aprendizagem, a Educação Física é uma disciplina em que o contato físico entre os alunos é grande, por intermédio das diversas práticas que a compõem. Ela pode, segundo Pereira (2014), contribuir para que os alunos se tornem cidadãos críticos e participativos dentro da sociedade, conscientes de seus deveres e direitos. Dessa forma, os professores devem estar preparados para combater o bullying praticado entre os alunos, adquirindo conhecimentos para analisar a agressões e suas consequências, promovendo ações de prevenção para tornar o ambiente escolar harmonioso para o convívio e aprendizagem.

As ações de prevenção e combate são relativamente simples e de baixo custo e devem ser um trabalho continuado por toda a comunidade, incluído no cotidiano das escolas, inserindo os temas transversais em todos os momentos da vida escolar. (LOPES NETO, 2005).

Além dos temas transversais, Carvalho (2012) aponta o jogo como forma de diminuir o preconceito. Por meio de jogos, brincadeiras, atividades lúdicas concebidas, a prática das relações sociais pode ser desenvolvida, tornando um importante componente educativo. A partir dessas ações, as crianças vivenciam momentos de alegria, nos quais, em condições seguras, podem expressar sua agressividade e, ao mesmo tempo, respeitar e conviver com o outro.

A Educação Física é um ambiente muito propício pra intervenção. Eu acredito que através de conversa, de di-
álogos, apresentações e até mesmo utilizando jogos comparativos, jogos que por ventura venham diminuir a
intensidade do preconceito, tirando o estigma de que o gordinho não é capaz. Eu acredito que a Educação Física
tem um papel importante dentro da escola para amenizar essa situação e intervindo de forma direta no caso (p.5).

Para Pereira e Carvalho (2007), é possível que os professores ministrem atividades educativas para ouvir as reclamações dos alunos a respeito das ações de bullying. Isso pode ser uma estratégia persuasiva na prevenção e combate a esse fenômeno. Essas atividades educativas podem acontecer por 
meio dos jogos cooperativos, abordando o tema do respeito à diferença, da aceitação, da cooperação e do trabalho em equipe, visando que os alunos se tornem cidadãos empenhados com uma comunidade mais justa e democrática.

Dessa forma, é imprescindível a adoção de uma postura firme dos professores, tornando-se necessário desenvolver atividades educativas que promovam a compreensão dos alunos diante das manifestações de bullying nas aulas de Educação Física, de forma a criar e manter um ambiente saudável, no qual não seja tolerado que os discentes sejam intimidados, agredidos ou desrespeitados no ambiente escolar.

\section{CONSIDERAÇÕES FINAIS}

Em diversas ocasiões, os atos classificados como bullying são reflexos de problemas sociais que envolvem a família e/ou o meio social onde os agressores estão inseridos. Em se tratando do ambiente escolar, a Educação Física, por meio das ações promovidas pelo professor, reúne meios para programar estratégias que visem prevenir casos de bullying entre os alunos.

A partir das observações feitas pelos entrevistados, o presente estudo teve como objetivo compreender a comparência do fenômeno bullying nas aulas de Educação Física Escolar, a partir da visão dos professores que atuam em escolas no município de Volta Redonda, estado do Rio de Janeiro. Foi possível constatar que as incidências como educação no ambiente familiar, informações influenciadas pela mídia, imagem corporal, preconceito, falta de habilidade e relação pessoal colaboram para que ocorram casos de bullying durante as aulas de Educação Física e, como consequência, afetam o desenvolvimento do aluno, sua participação e envolvimento durante as aulas, prejudicando o convívio social, diminuindo o interesse pelo ambiente escolar, levando à evasão e até à depressão.

Diante do exposto, percebe-se o diálogo como maior meio de prevenir e combater as mais diversas formas de violência, como ofensas, brigas e desrespeito, para que o ambiente escolar possa ser um local seguro, tranquilo e agradável, que permitirá à criança aprender a socializar-se, desenvolver responsabilidades, discutir ideias e, acima de tudo, assumir uma autonomia que permita que o processo de ensino e aprendizagem ocorra de maneira satisfatória para todos. Dessa forma, as escolas pais e os professores de Educação Física precisam estar preparados para enfrentar o bullying e aptos a realizarem projetos de orientação aos alunos quanto à prática do fenômeno e suas consequências. 


\section{REFERÊNCIAS}

AGEE, Jane. Developing qualitative research questions: a reflective process. International Journal of Qualitative Studies, v. 22, n. 4, p. 431-447, 2009.Disponívelem:<http://dx.doi.org/10.1080/09518390902736512>. Acesso em: 6 set. 2014.

BARDIN, Laurence. Análise de conteúdo. São Paulo: Edições 70, 2011.

BOMFIM, Daiane. Lopes. et al. Ocorrência de bullying nas aulas de educação física em uma escola do Distrito Federal. Pensar a Prática, Goiânia, v. 15, n. 2, p. 302-317, abr/jun., 2012. Disponível em: <http:// www.revistas.ufg.br/index.php/fef/article/view/12520/11202>. Acesso em: 20 out. 2014.

BORREANI, Claudia. et al. An increasing number of qualitative research papers in oncology and palliative care: does it mean a thorough development of the methodology of research?.Health and Quality of Life Outcomes, v. 2, n. 7, p. 431-447, 2004.Disponível em: <http://www.ncbi.nlm.nih.gov/pubmed/14741052>. Acesso em: 20 out. 2014.

BOYLE, Spencer Earl et al. Physical activity among adolescents and barriers to delivering physical education in Cornwall and Lancashire, UK: a qualitative study of heads of PE and heads of schools. BMC Public Health, v. 8, n. 273, 2008. Disponível em :<http://www.biomedcentral.com/1471-2458/8/273>. Acesso em: 8 set. 2014.

BOZI, Luiz Henrique Marchesi et al. Educação física escolar: principais formas de preconceito. Revista Digital, Buenos Aires, v. 12, n. 117, fev. 2008. Disponível em: <http://www.efdeportes.com/efd117/ educacao-fisica-escolar-principais-formas-de-preconceito.htm>. Acesso em: 18 fev. 2015.

CARVALHO, João Eloir. Os benefícios das atividades lúdicas para a prevenção do "bullying" no contexto escolar. Tese de Doutorado em Estudos da Criança - Instituto da Educação da Universidade do Minho. Braga, Gualtar. 2012. Disponível em: <http://hdl.handle.net/1822/23562 > Acesso: 12 mar. 2015.

CARVALHO, Alba Ataciane de Lima; SILVA, Maria Luciene. O bullying e a gestão democrática de escolas públicas: algumas reflexões. Olhares Plurais, Maceió, v. 1, n. 4, p. 81-98, 2011. Disponível em: <http:// revista.seune.edu.br/index.php/op/article/view/38>. Acesso: 18 fev. 2015.

COSTA, Thécia Pontes et al. A função do educador físico no enfrentamento do fenômeno bullying no âmbito escolar. Perspectivas online, Campos dos Goytacazes, v. 4, n. 2, p. 28-40, 2012. Disponível em: <http://www.seer.perspectivasonline.com.br/index.php/biologicas_e_saude/article/view/237/143>. Acesso: 12 mar. 2015.

FANTE, Cleo. Fenômeno bullying: como prevenir a violência nas escolas e educar para a paz. 2. ed. Campinas: Verus, 2005.

LEITE, Cleber Henrique de Almeida. Bullying e atividade física: perspectivas da psicologia do esporte. 2011. $39 \mathrm{f}$. Trabalho de Conclusão de Curso - Universidade Estadual Paulista, Instituto de Biociências de Rio Claro, UNESP, Rio Claro, 2011.Disponível em: <http://acervodigital.unesp.br/handle/unesp/164626?locale=pt_ BR>. Acesso: 18 fev. 2015.

LEVANDOSKI, Gustavo; CARDOSO, Fernando Luiz. Percepção docente sobre as relações de agressividade, o lúdico e o "bullying" na escola. Pensar a Prática, Goiânia, v. 13, n. 2, p. 1-13, maio/ago., 2010.Disponível em: <http://www.revistas.ufg.br/index.php/fef/article/view/8517>. Acesso: 18 fev. 2015. 
LOPES NETO, Aramis Antônio. Bullying: saber identificar e como prevenir. São Paulo: Brasiliense, 2011. Bullying - comportamento agressivo entre os estudantes. Jornal de Pediatria - Vol. 81, n 5 (Supl.), 2005.

MASCARENHAS, Suely. Gestão do "bullying" e da indisciplina e qualidade do bem-estar psicossocial de docentes e discentes do Brasil (Rondônia). Psicologia, Saúde e Doenças, 2006. Disponível em: <http:// www.scielo.oces.mctes.pt/pdf/psd/v7n1na08.pd

f>. Acesso em: 04 mar. 2015.

MARCHESI, Álvaro. 0 que será de nós, os maus alunos? Porto Alegre: Ed Artmed, 2006.

MEDEIROS, Pâmella et al. "Bullying" e a relação entre atividade física e motora:uma revisão sistemática. Cinergis, v. 15, n. 3, jul/set., 2014. Disponível em <http://online.unisc.br/seer/index.php/cinergis>. Acesso em: 25 fev. 2015.

MELO,Josevaldo Araújo. Bullying na escola. São Paulo: Edupe, 2010.

MINAYO, Maria Cecília de Souza. 0 desafio do conhecimento: pesquisa qualitativa em saúde. 12. ed. São Paulo: Hucitec, 2010.

MOREIRA, Dirceu. Transtorno do assédio moral bullying: a violência silenciosa. São Paulo: Brasiliense, 2011.

MOURA, Everlaine Santiago de. 0 bullying na escola: o olhar dos professores. $2011.73 \mathrm{f}$. Trabalho de Conclusão de Curso. Universidade de Brasília, Faculdade de Educação, UnB, Brasília, 2011.

OLIVEIRA, Rogério Cruz de; DAÓLIO, Jocimar. Educação física, cultura e escola: da diferença como desigualdade à alteridade como possibilidade. Movimento, Porto Alegre, v. 16, n. 1, p. 149-167, jan./ março, 2010. Disponível em: <http://seer.ufrgs.br/index.php/Movimento/article/view/8279>. Acesso em: 25 fev. 2015.

PEREIRA, Beatriz Oliveira; CARVALHO, Graça Simões. Jogos e brinquedos nos recreios das escolas: atividade física, saúde e lazer. Modelos de análise e intervenção. Lisboa: Lidel- Edições técnicas, 2007.

PEREIRA, Patrícia José. 0 bullying nas aulas de Educação Física e o papel do Professor de Educação Física. Trabalho de Conclusão de Curso - Programa UAB da Universidade de Brasília - EDF 12 - Buritis/ MG. 2014.

PINHEIRO, Paulo Sérgio. World report on violence against children. New York: United Nations.2006.

REVISTA EF. Combate ao bullying nas escolas. Entrevistada Tânia Carvalho Netto. Entrevista concedida ao CONFEF - Confederação Nacional de Educação Física, 2010. Disponível em: <http://www.confef. org.br/extra/revistaef/arquivos/2010/N38_DEZEM

BRO/11_COMBATE_AO_BULLYING_NAS_ESCOLAS.pdf> Acesso em 13 mar. 2015.

SILVA, Ana Beatriz Barbosa. Bullying: mentes perigosas nas escolas. Rio de Janeiro: Objetiva, 2010. 
SILVA, Júnior Vagner Pereira da et al.Educação física e conteúdos trabalhados nas séries iniciais do ensino fundamental. Motriz, Rio Claro, v. 15, n. 3, p. 592-599, jul/set., 2009. Disponível em: <http://www. periodicos.rc.biblioteca.unesp.br/index.php/motriz/article/view/2945/2476>. Acesso em: 25 fev. 2015.

SILVA, José Edmilson da; SILVA, Carlos Alberto Figueiredo da. Educação física, folclore e religião: relações e interferências. Revista da Educação Física/UEM, Maringá, v. 20, n. 4, p. 555-567, 4. trim., 2009. Disponível em: <http://www.periodicos.uem.br/ojs/index.php/RevEducFis/article/view/6323>. Acesso em: 25 fev. 2015.

SOUZA JUNIOR, Marcílio Barbosa Mendonça et al. A análise de conteúdo como forma de tratamento dos dados numa pesquisa qualitativa em educação física escolar. Revista Movimento, Porto Alegre, $\mathrm{v}$. 16, n. 3, p. 31-49, jul/set. 2010. Disponível em: <http://seer.ufrgs.br/Movimento/article/view/11546>. Acesso em: 06 set. 2014.

TEIXEIRA, Gustavo. Manual antibullying: para alunos, pais e professores. Rio de Janeiro: BestSeller, 2011.

THOMAS, Jerry. R., NELSON, Jack. K.; SILVERMAN, Stephen.J. Métodos de pesquisa em atividade física. 6. ed. Porto Alegre: Artmed, 2012. 